\title{
Restoration techniques of fractured endodontically treated teeth
}

\author{
Abdullah Fahad Al-Hussain ${ }^{1 *}$, Mohammed Mesfer Alkhathami ${ }^{2}$, Khalid Mabrouk Almesfer ${ }^{3}$, \\ Abdulrahman Madwas Mohammed ${ }^{4}$, Abdullah Mansour AlRajeh ${ }^{4}$, Mohammed Ali Alasmri ${ }^{5}$, \\ Ohud Awwadh Kehaili ${ }^{6}$, Sultan Falah Alresheedi ${ }^{7}$, Ahmed Fadgoosh Alotaibi ${ }^{4}$, \\ Muqbil Jazaa Almutairi ${ }^{8}$, Wesam Yousef Alibrahim ${ }^{4}$
}

\author{
${ }^{1}$ Department of Advanced General Dentistry, Ministry of National Guards Health Affairs, Riyadh, Saudi Arabia \\ ${ }^{2}$ Department of Endodontics, Dammam Medical Complex, Dammam, Saudi Arabia \\ ${ }^{3}$ Department of Dental Services, Ministry of National Guards Health Affairs, Riyadh, Saudi Arabia \\ ${ }^{4}$ General Dentist, Ministry of Health, Riyadh, Saudi Arabia \\ ${ }^{5}$ Abha Primary Health Care, Ministry of Health, Abha, Saudi Arabia \\ ${ }^{6}$ General Dentist, Dental Specialist Center, Tabuk, Saudi Arabia \\ ${ }^{7}$ General Dentist, Qassim Regional Dental Center, Buraydah, Saudi Arabia \\ ${ }^{8}$ General Dentist, Ministry of Health, Onaizah, Saudi Arabia
}

Received: 17 July 2021

Accepted: 20 July 2021

\section{*Correspondence:}

Dr. Abdullah Fahad Al-Hussain,

E-mail: dr.abdullahalhussain@gmail.com

Copyright: () the author(s), publisher and licensee Medip Academy. This is an open-access article distributed under the terms of the Creative Commons Attribution Non-Commercial License, which permits unrestricted non-commercial use, distribution, and reproduction in any medium, provided the original work is properly cited.

\begin{abstract}
This literature review aims to discuss and collect evidence about restoration techniques of fractured endodontically treated teeth. According to studies in the literature, root canal treatment and restoration of endodontically treated teeth have been reported as two separate clinical procedures although many aspects of both procedures are similar. Conducting restoration procedures following endodontic treatment has been reported to be so important as the first obturation of the root canal, and it has been reported with many advantages and favorable events, including eradication and minimizing the presence of bacteria and microorganisms, which might induce serious complications to the affected teeth. Additionally, the literature review discusses the technique of interim restorations, which has been reported to have favorable advantages and outcomes. However, it should be noted that the process is temporary and definitive restorations must be conducted later on. Also, this research investigates the different substances that should be used with the modality, and the different approaches that were previously reported to restore mature and immature affected teeth. Finally, evidence shows that amalgam-based restorations are becoming inferior to resin composite-based restorations which are also more superior to the stainless-steel crown-based ones. Unifying the guidelines for clinical practice is encouraged to obtain favorable outcomes. All the detailed techniques are presented and fully discussed within the main text of this research.
\end{abstract}

Keywords: Dentistry, Management, Endodontics, Restorations

\section{INTRODUCTION}

According to studies in the literature, root canal treatment and restoration of endodontically treated teeth have been reported as two separate clinical procedures although many aspects of both procedures are similar. Conducting restoration procedures following endodontic treatment has been reported to be so important as the first obturation of the root canal, and it has been reported with many advantages and favorable events, including eradication and minimizing the presence of bacteria and microorganisms, which might induce serious complications to the affected teeth. ${ }^{1-3}$ Many investigations have been published 
regarding the restoration techniques that were reported with various types of fractures following endodontic treatment modalities. However, no clear guidelines and protocols were drawn for such procedures. ${ }^{4,5}$ Accordingly, this literature review aims to discuss and collect evidence about restoration techniques of fractured endodontically treated teeth.

\section{METHODS}

This literature review is based on an extensive literature search in Medline, Cochrane, and EMBASE databases on 4th June 2021 using the medical subject headings (MeSH), and a combination of all possible related terms. This was followed by the manual search for papers in Google Scholar and the reference lists are included at the end of this research. ${ }^{6,7}$ This research discusses the restoration techniques of fractured endodontically treated teeth that were screened for relevant information. There are no limits on date, language, age of participants, or publication type. Many techniques have been previously proposed for restoring the fractured teeth during endodontic treatment. The following section discusses the common techniques and the various aspects that should be considered during the clinical settings that should be considered by the attending dentists and surgeons.

\section{DISCUSSION}

\section{Interim restorations}

Provisional, interim, or temporary restorations must be effectively done with materials that prevent leakage to intervene against the progression of any microleakage events and the development of bacterial-related adverse reactions. ${ }^{8-10}$ It was previously demonstrated that coronal microleakage is estimated to be the most common cause of endodontic treatment failure. Contamination of the root canal due to incompetent restorations can significantly lead to endodontic treatment failure and periapical inflammation. Obtaining a poor coronal seal was previously reported with performing interim restorations. ${ }^{11,12}$ They mainly depend on providing shortterm effective functions and esthetics, with preservation of the hard and soft tissues intact and with no complications until the establishment of the definitive restorations are performed. Additionally, a previous investigation reported that following root canal therapy results in better survival rates of the corresponding endodontic-treated teeth which were significantly associated with the early inauguration of interim restorations.13 Selecting the appropriate material is a challenge that should be considered when performing interim restorations, and the process mainly depends on the intended duration of the restoration. For instance, cement as zinc oxide eugenol (ZOE) should be used for short-term interim restorations that are indicated to last for a maximum duration of 1-2 weeks. ${ }^{14}$ On the other hand, more durable cement types should be used when the definitive restorations are expected to be delayed, as resinmodified glass ionomers (RMGIs), Glass ionomers,
Polycarboxylate, or Zinc Phosphate. These substances were previously reported to be more durable with favorable seals against dentin in the affected teeth, which allows them to be associated with both long and short-term outcomes with interim restorations. However, it should be noted that these substances can only be used for a while, and cannot replace definitive restorations. ${ }^{15}$ Using calcium sulfate for interim restorations was also previously reported in the literature. However, full removal of these fillings before definitive restorations are required to prevent the development of any potential complications. Moreover, it was previously demonstrated that neither Cavit $^{\mathrm{TM}}$, Intermediate Restorative Material (IRM ${ }^{\circledR}$ ), or TempBond ${ }^{\mathrm{TM}}$ were associated with adequate prevention of 30-day coronal leakage after being installed as interim restorations. ${ }^{11}$ It was also reported that interim restorations were associated with worse endodontic treatment prognosis when compared to definitive restorations, even if the latter was conducted later on. ${ }^{16}$

It should be noted that installing temporary restorations might be required between the different sessions to prevent the accumulation of bacteria in the root canal and intervene against the development of any complications. ${ }^{17}$ Maximizing the thickness of the used material and minimizing the height of the cotton pellet is recommended, in addition to using a sponge rather than cotton to reduce the rate of bacterial growth. ${ }^{18}$ In another context, provisional onlays or crowns might be indicated in severely damaged teeth, and many substances as resin composites and acrylic have been recommended for such purposes, which has been previously reported with both indirect and direct interim restorations, with the former providing more favorable marginal integrity than the latter. ${ }^{19}$ The installment of temporary posts might also be indicated together with the interim restorations for select premolar and coronally compromised anterior teeth. However, it should be noted that such a process should be approached with minimal cement materials for easy removal of the posts during definitive restorations. Zinc oxide-based cement materials are the main materials that have been used for luting provisional crowns whether the types containing eugenol or others without it. Among studies in the literature, evidence was controversial regarding using these materials with resin composites and their abilities to prevent polymerization and enhance the adherence to the underlying dentin..$^{20,21}$ Finally, all the materials and pellet cotton that has been used for interim restorations should be adequately removed before conducting definitive restorations to obtain better outcomes and enhance the prognosis of endodontic treatment.

\section{Techniques of restoring mature teeth}

Following obturation and before removing the dental dam, foundation restoration should be conducted immediately even when the symptoms and signs were not still absent following this procedure. Following this, it has been previously demonstrated that it is considered safe to 
remove the obturation materials. ${ }^{22}$ Endodontic treatment modalities can now be inaugurated and preparation of the post space modalities can be done during this procedure of following it, as previous investigations have reported that the leakage outcomes are similar irrespective of the time of post space preparation. ${ }^{23}$ However, interventions against potential contamination should be conducted at all stages. Using a composite resin buildup and a fabricated post can then be used for the restoration of the structural compromisation of an anterior tooth. However, it should be noted that the cemented post might be only attached to the most apical area within the post space when it is too wide. This can lead to the development of significant complications due to the potential breakdown of the cemented post leading to leakage, post-retention loss, caries, and failure of the crown. Using custom cast posts was also recommended for certain situations with loss of main structures of the tooth and root canal, aiming at achieving better adaptation with the new morphology of the root canal. It should be noted that removing the obturation materials by a single millimeter beneath the floor of the pulp is recommended. Besides, excess sealers should also be removed because, for instance, zinc oxidebased ones can significantly lead to the inhibition of polymerization, and it can lead to preventing the glass ionomer potential adhesions to the corresponding dentin. ${ }^{24}$

It has been previously reported that the majority of the affected anterior teeth can be successfully restored using dental resin composites. It is also recommended that the structure of the tooth should be preserved as much as possible because root canal filling is usually associated with thinning of the tooth wall, in addition to the weakness noticed with crown preparations. ${ }^{25}$ In fractured anterior teeth with no access opening, it is recommended that direct restoration of the lost parts is preferred to obtain better outcomes with no further impact on the remaining structure of the tooth. After pacing the gutta-percha below the cementoenamel junction by few millimeters, using a glass ionomer is required to decrease the need for excess bulk of resin composites and to preserve the materials that were used in the root filling process. Although the installation of posts does not strengthen the affected teeth, they prevent any further weakening of these teeth by preventing any further dentin removal. ${ }^{26,27}$ To establish a corona-radicular workup in a posterior tooth, 2-3 intact walls are necessary. ${ }^{27,28}$ Early sealing of the canal should also be sought with suitable barriers as hydrophilic resin, flowable composite resin, or glass ionomer if early restoration could not be obtained. ${ }^{29,30}$ For premolars with retained palatal and buccal walls, they can be normally restored by approaching a core buildup as definitive restorations with no need for post-placement modalities. Many studies have been previously published and guidelines were announced to report on the suitable characteristics of the process of post-placement. ${ }^{31,32}$ However, it was also reported that irrespective of the type and characteristics of the used posts, using a cervical ferrule should be approached by $2 \mathrm{~mm}$ to the tooth structure to prevent any potential fractures to the root. ${ }^{33}$

\section{Techniques of restoring immature teeth}

The main goal of restoration of these teeth is to preserve as much as possible of the affected structure. Previous investigations have reported that stainless steel crowns or preformed metal crowns should be used for immature teeth until placing the implants for these affected teeth with space maintenance to prevent any potential complications because these teeth are more prone to fractures and other subsequent adverse events. ${ }^{34,35}$ Other more recent investigations have evaluated the use of regenerative techniques and innovative obturation modalities through the application of different materials as mineral trioxide aggregate and bioceramics that have been previously reported to stimulate the growth of the nerve roots within a dead or necrotic tooth tissue. These effects, in addition to increasing the thickness of the walls of the affected teeth, have been indicated by previous investigations. ${ }^{36,37}$ Using amalgam as the core material for dental restorations, successful procedures were reported with affected teeth that have been observed with huge loss of the coronal structures. ${ }^{38}$ However, it has been reported that using amalgam instead of dentin in such procedures can significantly increase the risk of complications as contamination and bacterial infections, in addition to fractures. ${ }^{35,39,40}$ Accordingly, adopting stainless steel crowns in such procedures is recommended to prevent potential crown fractures and other complications as microleakage and bacterial contamination. ${ }^{35}$ These modalities were previously validated with no or reduced adverse events on periodontal health. On the other hand, poor installation and adjustment of the modality have been previously reported to cause inflammation and increased risk of the compromised periodontium, in addition to potential microleakage and tooth affection. ${ }^{38,41,42}$ It has been previously demonstrated that translucent cores of resin composites are also effective materials that can be used in restoration procedures with favorable outcomes, with reported improved strengths and resistance to fractures decreasing the need to perform further preparation and retention procedures. It was also reported that these materials reduce the time taken to polymerization, and therefore, enhancing the relevant outcomes. $^{43}$ Many materials have been reported in the literature and validated by various studies, and among them, Light-Core ${ }^{\mathrm{TM}}$ (Bisco, Inc., Schaumburg, IL, USA), Build-It ${ }^{\mathrm{TM}}$ (Pentron, Inc. Orange, CA, USA), and Clearfil ${ }^{\mathrm{TM}}$ Photo Core (Kuraray Co. Ltd., Osaka, Japan) are reported to be efficacious. ${ }^{44}$ Recently, it has been demonstrated that composite restorations are becoming more popular than amalgam-based ones, however, higher replacement rates have been reported. ${ }^{45}$ Within the surgical settings of primary teeth restorations with vital pulps, studies are indicating that composites are rapidly replacing amalgam-based restorations and the reported favorable outcomes with the former are increasing with time due to the recent technological advances in the field. ${ }^{46,47}$ Using these modalities has been reported with many advantages including the effective preservation of the affected tooth structure, which is even more efficacious than using the 
stainless steel crown modalities and the amalgam-based restoration approaches. ${ }^{48,49}$

\section{CONCLUSION}

This literature review discusses and gathers evidence about restoration techniques of fractured endodontically treated teeth from various studies in the literature. Also, it discusses the technique of interim restorations, which has been reported to have favorable advantages and outcomes. However, it should be noted that the process is temporary and definitive restorations must be conducted later on. In addition, this research reviewes the different substances that should be used with the modality, and the different approaches that were previously reported to restore mature and immature affected teeth. Finally, evidence shows that amalgam-based restorations are becoming inferior to resin composite-based restorations which are also more superior to the stainless steel crown-based ones. Unifying the guidelines for clinical practice is encouraged to obtain favorable outcomes.

\section{Funding: No funding sources \\ Conflict of interest: None declared \\ Ethical approval: Not required}

\section{REFERENCES}

1. Ng YL, Mann V, Gulabivala K. A prospective study of the factors affecting outcomes of nonsurgical root canal treatment: part 1: periapical health. International endodontic journal. 2011;44(7):583609.

2. Ng YL, Mann V, Gulabivala K. A prospective study of the factors affecting outcomes of non-surgical root canal treatment: part 2: tooth survival. International endodontic journal. 2011;44(7):610-25.

3. Gillen BM, Looney SW, Gu LS. Impact of the quality of coronal restoration versus the quality of root canal fillings on success of root canal treatment: a systematic review and meta-analysis. Journal of endodontics. 2011;37(7):895-902.

4. Morgano SM, Milot P. Clinical success of cast metal posts and cores. The Journal of prosthetic dentistry. 1993;70(1):11-16.

5. Bader JD, Shugars DA, Roberson TM. Using crowns to prevent tooth fracture. Community dentistry and oral epidemiology. 1996;24(1):47-51.

6. Hashan MR, Ghozy S, El-Qushayri AE, Pial RH, Hossain MA, Al Kibria GM. Association of dengue disease severity and blood group: A systematic review and meta-analysis. Rev Med Virol. 2021;31(1):1-9.

7. El-Qushayri AE, Ghozy S, Abbas AS. Hyperimmunoglobulin therapy for the prevention and treatment of congenital cytomegalovirus: a systematic review and meta-analysis. Expert Rev Anti Infect Ther. 2020:1-9.

8. Saunders WP, Saunders EM. Coronal leakage as a cause of failure in root-canal therapy: a review.
Endodontics \& dental traumatology. 1994;10(3):1058.

9. Heling I, Gorfil C, Slutzky H, Kopolovic K, Zalkind M, Slutzky-Goldberg I. Endodontic failure caused by inadequate restorative procedures: review and treatment recommendations. The Journal of prosthetic dentistry. 2002;87(6):674-8.

10. Trope M, Chow E, Nissan R. In vitro endotoxin penetration of coronally unsealed endodontically treated teeth. Endodontics \& dental traumatology. 1995;11(2):90-4.

11. Balto H, Al-Nazhan S, Al-Mansour K, Al-Otaibi M, Siddiqu Y. Microbial leakage of Cavit, IRM, and Temp Bond in post-prepared root canals using two methods of gutta-percha removal: an in vitro study. The journal of contemporary dental practice. 2005;6(3):53-61.

12. Lynch CD, Burke FM, R NR, Hannigan A. The influence of coronal restoration type on the survival of endodontically treated teeth. The European journal of prosthodontics and restorative dentistry. 2004;12(4):171-6.

13. Willershausen B, Tekyatan H, Krummenauer F, Briseño Marroquin B. Survival rate of endodontically treated teeth in relation to conservative vs post insertion techniques -- a retrospective study. European journal of medical research. 2005;10(5):204-8.

14. Imura N, Otani SM, Campos MJ, Jardim Júnior EG, Zuolo ML. Bacterial penetration through temporary restorative materials in root-canal-treated teeth in vitro. International endodontic journal. 1997;30(6):381-5.

15. Todd MJ, Harrison JW. An evaluation of the immediate and early sealing properties of Cavit. Journal of endodontics. 1979;5(12):362-7.

16. Safavi KE, Dowden WE, Langeland K. Influence of delayed coronal permanent restoration on endodontic prognosis. Endodontics \& dental traumatology. 1987;3(4):187-91.

17. Jensen AL, Abbott PV, Castro Salgado J. Interim and temporary restoration of teeth during endodontic treatment. Australian dental journal. 2007;52(1):S8399.

18. Naoum HJ, Chandler NP. Temporization for endodontics. International endodontic journal. 2002;35(12):964-78.

19. Ehrenberg DS, Weiner S. Changes in marginal gap size of provisional resin crowns after occlusal loading and thermal cycling. The Journal of prosthetic dentistry. 2000;84(2):139-48.

20. Ribeiro JC, Coelho PG, Janal MN, Silva NR, Monteiro AJ, Fernandes CA. The influence of temporary cements on dental adhesive systems for luting cementation. Journal of dentistry. 2011;39(3):255-62.

21. Peutzfeldt A, Asmussen E. Influence of eugenolcontaining temporary cement on bonding of selfetching adhesives to dentin. The journal of adhesive dentistry. 2006;8(1):31-4. 
22. Torabinejad M, Anderson P, Bader J. Outcomes of root canal treatment and restoration, implantsupported single crowns, fixed partial dentures, and extraction without replacement: a systematic review. J Prosthetic Dent. 2007;98(4):285-311.

23. Neagley RL. The effect of dowel preparation on the apical seal of endodontically treated teeth. Oral Surg Oral Med Oral Pathol. 1969;28(5):739-45.

24. Macchi RL, Capurro MA, Herrera CL, Cebada FR, Kohen S. Influence of endodontic materials on the bonding of composite resin to dentin. Endodontics \& dental traumatology. 1992;8(1):26-9.

25. Edelhoff D, Sorensen JA. Tooth structure removal associated with various preparation designs for posterior teeth. The Int J Periodontics Restorative Dent. 2002;22(3):241-9.

26. Goodacre CJ, Bernal G, Rungcharassaeng K, Kan JY. Clinical complications in fixed prosthodontics. J Prosthetic Dent. 2003;90(1):31-41.

27. Nayyar A, Walton RE, Leonard LA. An amalgam coronal-radicular dowel and core technique for endodontically treated posterior teeth. The Journal of prosthetic dentistry. 1980;43(5):511-5.

28. Starr CB. Amalgam crown restorations for posterior pulpless teeth. The Journal of prosthetic dentistry. 1990;63(6):614-9.

29. Celik EU, Yapar AG, Ateş M, Sen BH. Bacterial microleakage of barrier materials in obturated root canals. Journal of endodontics. 2006;32(11):1074-6.

30. Yamauchi S, Shipper G, Buttke T, Yamauchi M, Trope M. Effect of orifice plugs on periapical inflammation in dogs. Journal of endodontics. 2006;32(6):524-6.

31. Mondelli J, Piccino AC, Berbert A. An acrylic resin pattern for a cast dowel and core. The Journal of prosthetic dentistry. 1971;25(4):413-7.

32. Leary JM, Aquilino SA, Svare CW. An evaluation of post length within the elastic limits of dentin. The Journal of prosthetic dentistry. 1987;57(3):277-81.

33. Pereira JR, de Ornelas F, Conti PC, do Valle AL. Effect of a crown ferrule on the fracture resistance of endodontically treated teeth restored with prefabricated posts. The J Prosthetic Dent. 2006;95(1):50-4.

34. Croll TP. Permanent molar stainless steel crown restoration. Quintessence international (Berlin, Germany: 1985). 1987;18(5):313-21.

35. Murray RR, Madden PW. Amalgam-reinforced stainless steel crown for restoration of permanent molars. Operative Dent. 1997;22(1):41-4.

36. Shabahang S. Treatment options: apexogenesis and apexification. J Endodont. 2013;39(3):S26-9.

37. Jeeruphan T, Jantarat J, Yanpiset K, Suwannapan L, Khewsawai P, Hargreaves KM. Mahidol study 1: comparison of radiographic and survival outcomes of immature teeth treated with either regenerative endodontic or apexification methods: a retrospective study. Journal of endodontics. 2012;38(10):1330-6.
38. Radcliffe RM, Cullen CL. Preservation of future options: restorative procedures on first permanent molars in children. ASDC journal of dentistry for children. 1991;58(2):104-8.

39. Akerboom HB, Advokaat JG, Van Amerongen WE, Borgmeijer PJ. Long-term evaluation and rerestoration of amalgam restorations. Community dentistry and oral epidemiology. 1993;21(1):45-8.

40. Forss H, Widström E. The post-amalgam era: a selection of materials and their longevity in the primary and young permanent dentitions. International journal of paediatric dentistry. 2003;13(3):158-64.

41. Checchio LM, Gaskill WF, Carrel R. The relationship between periodontal disease and stainless steel crowns. ASDC journal of dentistry for children. 1983;50(3):205-9.

42. White SN, Ingles S, Kipnis V. Influence of marginal opening on microleakage of cemented artificial crowns. The Journal of prosthetic dentistry. 1994;71(3):257-64.

43. Taha NA, Palamara JE, Messer HH. Fracture strength and fracture patterns of root filled teeth restored with direct resin restorations. Journal of dentistry. 2011;39(8):527-35.

44. Rüttermann S, Alberts I, Raab WH, Janda RR. Physical properties of self-, dual-, and light-cured direct core materials. Clinical oral investigations. 2011;15(4):597-603.

45. Randall RC. Preformed metal crowns for primary and permanent molar teeth: review of the literature. Pediatric dentistry. 2002;24(5):489-500.

46. Soncini JA, Maserejian NN, Trachtenberg F, Tavares $\mathrm{M}$, Hayes $\mathrm{C}$. The longevity of amalgam versus compomer/composite restorations in posterior primary and permanent teeth: findings From the New England Children's Amalgam Trial. Journal of the American Dental Association (1939). 2007;138(6):763-72.

47. Lempel E, Tóth Á, Fábián T, Krajczár K, Szalma J. Retrospective evaluation of posterior direct composite restorations: 10-year findings. Dental material: official publication of the Academy of Dental Materials. 2015;31(2):115-22.

48. Dennison JB, Hamilton JC. Treatment decisions and conservation of tooth structure. Dental clinics of North America. 2005;49(4):825-45.

49. Slutzky-Goldberg I, Slutzky H, Gorfil C, Smidt A. Restoration of endodontically treated teeth review and treatment recommendations. Int $\mathbf{J}$ Dent. 2009;2009:150251.

Cite this article as: Al-Hussain AF, Alkhathami MM, Almesfer KM, Mohammed AM, AlRajeh AM, Alasmri MA et al. Restoration techniques of fractured endodontically treated teeth. Int J Community Med Public Health 2021;8:4123-7. 